\title{
Study on the thermal load of the laser impulse metal bonding process to the metallized thermal sensitive substrate
}

\author{
W.-S. Chung ${ }^{1}$ (D) F. Nagel ${ }^{1} \cdot$ A. Olowinsky ${ }^{1} \cdot$ A. Gillner ${ }^{1,2}$ \\ Received: 30 October 2019 / Accepted: 24 November 2020 / Published online: 3 December 2020 \\ (C) The Author(s) 2020
}

\begin{abstract}
The laser impulse metal bonding (LIMBO) process opens a new possibility to join a thick interconnector on a thin metal layer which lays on a sensitive substrate such as epoxy resin (FR4) material. Since the FR4 tolerates only limited amount of the thermal load during the joining process, the LIMBO process applies a novel approach to separate the melting and joining phase. Hence, the thermal load on the underlying substrate during the joining phase is minimized and therefore allows a welding approach even for electric as well as electronic components. However, the substrate is thermally affected due to the heat conduction which is induced during the joining phase. In this paper, the thermal cycle induced to the sensitive substrate during the LIMBO process and the overlap welding process for enlarging the weld joint area will be investigated. To evaluate the maximal amount of thermal load on the sensitive substrate below a thin copper layer by given setting, the thermal destruction threshold of substrate is exceeded on purpose. For the understanding of the heat distribution during the joining stage, the experimental results are validated with simulation results.
\end{abstract}

Keywords LIMBO $\cdot$ Thermal load $\cdot$ Heat conduction $\cdot$ Thermal simulation $\cdot$ Overlap welding

\section{Introduction}

The high brilliant laser beam source with sufficient laser beam intensity is used to process a highly thermal conductive material such as copper [1] or aluminum [2] to encounter their high heat conductivity and the low laser beam absorptivity in infrared wavelength regime. Furthermore, a precise control of the energy input enables to limit the energy amount into the processing substrates and therefore suitable for various materials [3-5]. However, even with the usage of the high brilliant laser beam source, the conventional laser beam welding process shows difficulties to be applied for welding of interconnectors to metallized substrates due to the thermal overload.

Recommended for publication by Commission VII - Microjoining and Nanojoining

W.-S. Chung

woo-sik.chung@ilt.fraunhofer.de

1 Fraunhofer Institute for Laser Technology ILT, Steinbachstr. 15, 52074 Aachen, Germany

2 Chair of Laser Technology LLT, Steinbachstr. 15, 52074 Aachen, Germany
The laser impulse metal bonding (LIMBO) process applies an innovation approach to divide the melting and joining phase by the spatial separation of base materials with a defined gap around $100 \mu \mathrm{m}[6,7]$. The heat conduction to the underlying substrate is only given when the deflected melt pool of upper base material bridges the gap and wets on the surface. As soon as the deflected melt pool wets on the underlying substrate surface, the heat conduction is initiated. The advantage of LIMBO process is a control of the explicit welding duration under $t<1 \mathrm{~ms}$ [8].

However, this advantage of the LIMBO process is only given before a subsequent pulse is irradiated next to the previous weld joint to enlarge the weld joint diameter [6]. Throughout the previously conducted weld joint, both base materials are already joined. As a consequence, a clear separation of the melting and joining process is not guaranteed and allows a heat conduction during the whole welding process.

In this paper, the thermal influence during the joining stage will be discussed in terms of the critical substrate damage by experiment and simulation. The crucial duration of heat conduction will be investigated based on the experimental results and evaluated with the simulation results. The understanding of the thermal threshold of the substrate will be transferred to the overlap welding process. Based on the investigation, the temperature distribution of previously conducted weld joint during the 
expansion process will be assumed. As a result, the main influence factor for the heat distribution as well as thermal damage will be discussed further.

\section{State of the art}

\subsection{Laser impulse metal bonding}

The LIMBO process requires spatially separated base materials with a defined gap around $100 \mu \mathrm{m}$. To realize a weld joint over a gap, the LIMBO process is divided into four phases: pre-heating, deflection, joining, and expansion stage. The LIMBO process is schematically represented in Fig. 1.

In the pre-heating stage, the upper base material is locally exposed to a laser beam until a 'lens-like' melt is formed at the lower side of the upper base material. The generation of 'lens-like' melt is observed when the upper base material is locally molten through. In the following deflection stage, the laser beam is modulated to rapidly vaporize the melt surface. Due to the sudden vaporization of the melt pool, a metal plume recoil pressure is induced which accelerates the melt to the underlying base material. When the accelerated melt bridges the gap between both base materials, the joining stage begins. After the wetting of the melt on the copper layer, the stored heat energy in the melt and further energy input of the laser beam starts to melt the copper layer. Consequently, the melt penetrates into the copper layer and forms a weld joint after a solidification. The expansion stage is a repetition of first three stages of the LIMBO process in one direction with defined overlap factor $O_{\mathrm{f}}$ with the equation [6]:

$O_{\mathrm{f}}=\left(1-x_{\text {Pulse }} / d_{\mathrm{t}}\right) \times 100 \%$

where $x_{\text {Pulse }}$ is the distance of each pulses and the $d_{\mathrm{t}}$ is the diameter of the solidified melt pool of upper base material after the first LIMBO process.

\subsection{Experimental set-up}

As for the upper base material, one-sided nickel-coated $\mathrm{Cu}$-ETP is selected to increase the absorptivity at the wavelength $\lambda=$ $1070 \mathrm{~nm}$ at the initial stage of the welding process. The dimension of the interconnector is $b \times 1=4 \mathrm{~mm} \times 20 \mathrm{~mm}$ with $0.2 \mathrm{~mm}$ thickness. The lower base material, so-called PCB with a thin copper layer (dimension $b \times 1=7 \mathrm{~mm} \times 18 \mathrm{~mm}$ with $0.1 \mathrm{~mm}$ thickness) on a glass fiber-reinforced epoxy resin (FR4), is selected. The temperature threshold for the epoxy resin is defined as the delamination temperature $T_{\mathrm{d}}=390^{\circ} \mathrm{C}$. The gap between both materials is realized with a thermal isolating material which has a thickness $0.06 \mathrm{~mm}$. The schematic representation of the experimental set-up and specimen is shown in Fig. 2.

A single-mode fiber laser source with the wavelength $\lambda=$ $1070 \mathrm{~nm}$ is used for the welding process. The maximum laser beam power is $P_{\max }=1 \mathrm{~kW}$ and the spot diameter of the laser beam at the focal position is $d_{\mathrm{s}}=36 \mu \mathrm{m}$. The laser beam is guided on the specimen surface through the beam collimation, z-shifter, galvanoscanner, and f-theta lens. The function of the zshifter is to move the focal position in vertical direction. This movement leads to a temporal variation of the beam size at the specimen surface. The focal lens in the telescope can move in one direction from its initial position from $z=0 \mathrm{~mm}$ up to $z= \pm$ $2 \mathrm{~mm}$, and as a consequence, the beam size can be enlarged up to $d_{\mathrm{s}}=296 \mu \mathrm{m}$, respectively.

The monitoring of the melt dynamic between both base materials requires a high-speed camera device to capture the shadow projection of the deflected melt and a strong light source to generate a shadow projection. Those devices should be aligned coaxially and the specimen is placed in between. As for the light source, a diode laser beam source with a wavelength $\lambda=940 \pm 10 \mathrm{~nm}$ is used for this experiment due to the low absorptivity by the copper specimen. The captured shadow projection is shown on the left side of the Fig. 2.
Fig. 1 Schematic representation of LIMBO process $[9,10]$
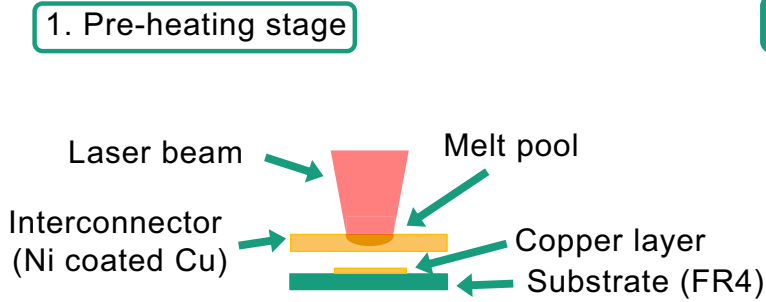

3. Joining stage

\section{Deflection stage}

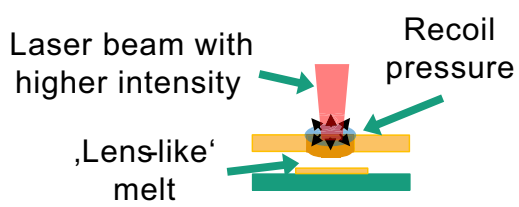

4. Expansion stage
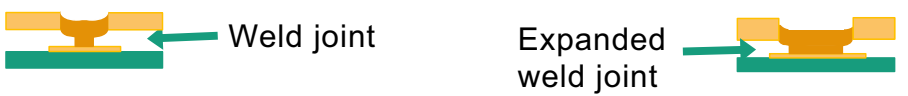


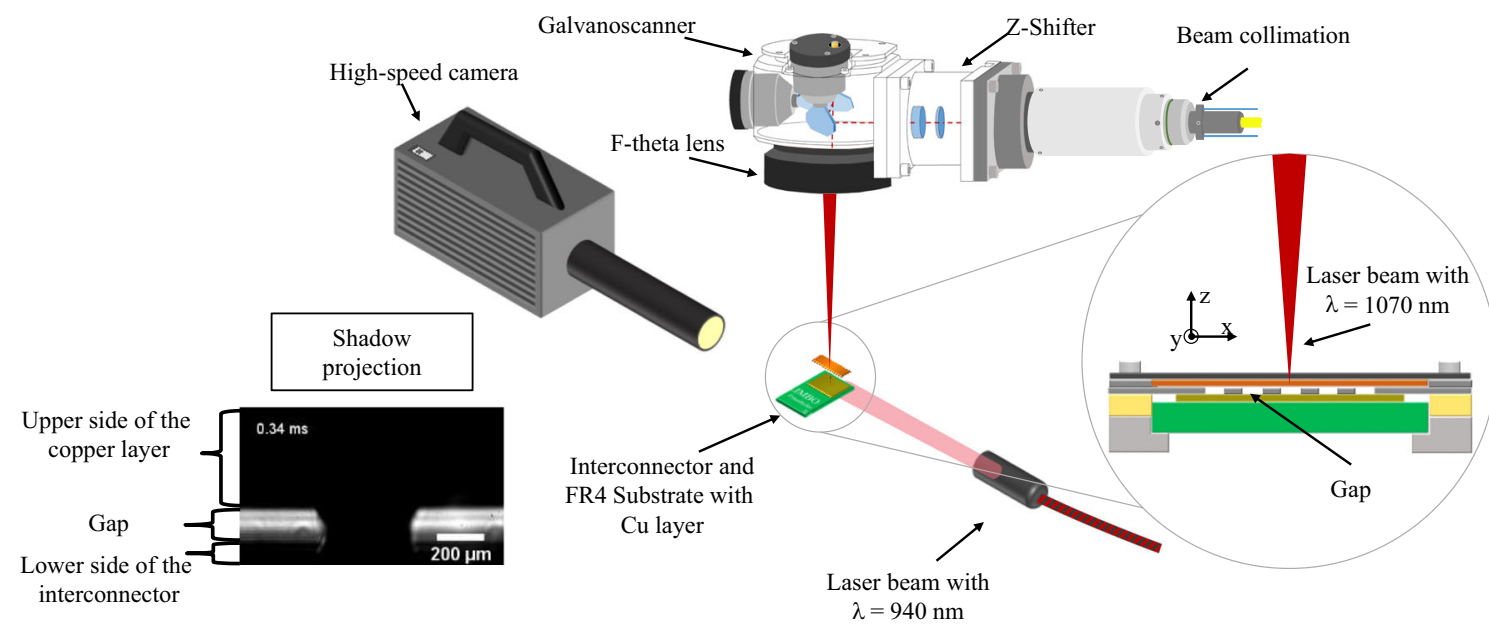

Fig. 2 Experimental set-up

\section{Boundary condition for the simulation}

\subsection{Heat conduction}

During the joining stage of the LIMBO process, a heat transfer from the upper base material to the underlying base material is initiated. The heat transfer to the substrate takes place when the deflected melt from the interconnector wets on the copper layer. The heat transfer mechanism of the LIMBO process is simulated with a simplified approach to describe the thermal load on the substrate and considers hereby only the heat conduction through the weld joint. The temperature at the interface between copper layer and substrate is considered to observe the thermal load at the sensitive substrate (refer to Fig. 3).

The COMSOL Multiphysics ${ }^{\circledR}$ "Structural Mechanics Module" with "Heat Transfer in Solids" is used to calculate the temperature distribution based on the heat transfer equation. The heat transfer equation for the two-dimensional simulation is described with the equation 2 :

$d_{\mathrm{y}} \rho c_{\mathrm{p}} \frac{\partial \mathrm{T}}{\partial \mathrm{t}}+d_{\mathrm{y}} \rho c_{\mathrm{p}} \vec{u} \nabla T+d_{\mathrm{y}} \nabla(-k \nabla T)=d_{\mathrm{y}} Q+d_{\mathrm{y}} Q_{\text {ted }}+q_{0}$

\section{Geometry $G_{1}$}
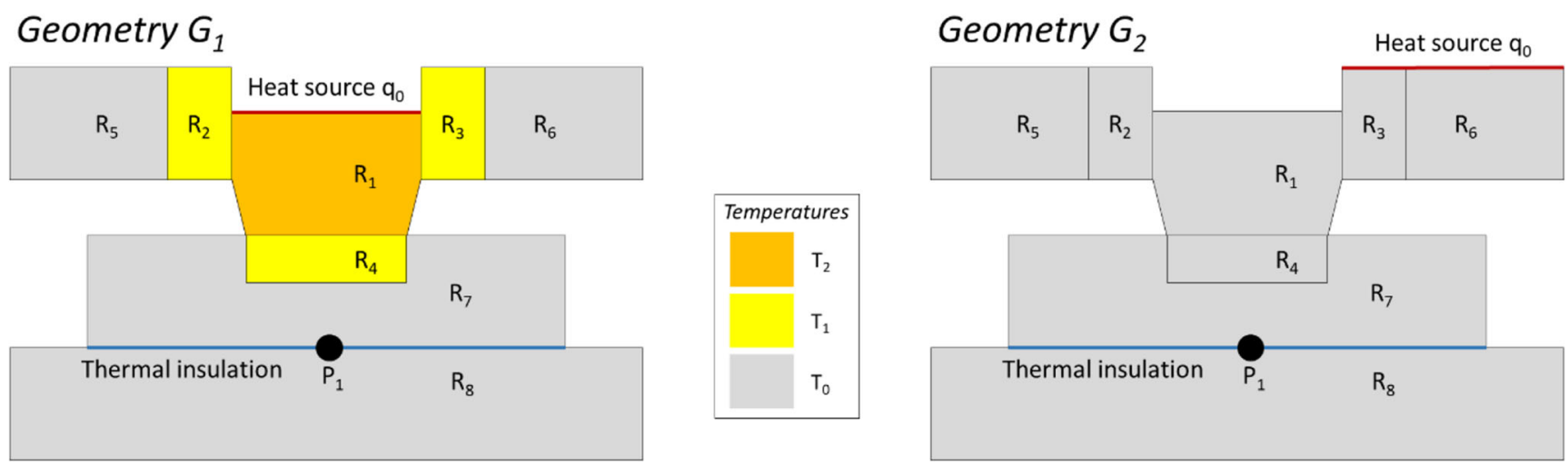

Fig. 3 Model for demonstrating the joining phase of LIMBO process. Left: model for the joining stage during the LIMBO process. Right: model for the pre-heating stage during the overlap welding process

$d_{\mathrm{y}}$ : length of the model on the $y$-axis $[\mathrm{m}] ; \rho$ : density $\left[\mathrm{kg} / \mathrm{m}^{3}\right] ; c_{\mathrm{p}}:$ specific heat capacity $[\mathrm{J} /(\mathrm{kg} \cdot \mathrm{K})] ; k$ : thermal conductivity $[\mathrm{W} /(\mathrm{m} \cdot \mathrm{K})] ; \mathrm{T}:$ temperature $[\mathrm{K}] ; \vec{u}$ : velocity field $[\mathrm{m} / \mathrm{s}]$; $Q:$ heat source $\left[\mathrm{W} / \mathrm{m}^{3}\right] ; Q_{\text {ted }}:$ thermoelastic damping $\left[\mathrm{W} / \mathrm{m}^{3}\right]$; $q_{0}$ : heat flux $\left[\mathrm{W} / \mathrm{m}^{2}\right]$.

The heat flux is described according to [9] where the heat accumulation through the absorption of the Gaussian laser beam profile is described with an equation 3 :

$q_{0}=\frac{2 P}{\pi w^{2}(z)} A \exp \left(-2\left(\frac{r}{w(z)}\right)^{2}\right)$

$q_{0} \quad$ heat flux $\left[\mathrm{W} / \mathrm{m}^{2}\right]$

$\mathrm{P} \quad$ power of the laser beam source [W]

A absorptivity [-]

$r \quad$ distance to the center of the heat source [m]

$w(z) \quad$ beam radius at the position $\mathrm{z}[\mathrm{m}]$

\subsection{Geometry for the simulation}

The melt dynamics are neglected during the simulation and only a static geometry is assumed. The static geometry of the 
LIMBO weld joint with different thermal load conditions is shown in Fig. 3. The given geometry is therefore simulated with two different locations for the heat source. The thermal load to the underlying substrate during the joining stage of LIMBO process (Fig. 3 left) and the pre-heating stage of overlap welding process (Fig. 3 right) are separately simulated. The interconnector is divided into five parts $R_{1}, R_{2}, R_{3}, R_{5}$, and $R_{6}$. The copper layer is represented by $R_{7}$ with an additional part $R_{4}$ and the substrate is represented by $R_{8}$.

\subsubsection{Joining stage of the LIMBO process}

A hexagon $R_{1}$ describes the melt pool which is deflected towards the copper layer. The width of the upper boundary of $R_{1}$ is set to $200 \mu \mathrm{m}$ where the laser beam is irradiated with a comparable laser beam diameter. The lower boundary of $R_{1}$ demonstrates a joint interface diameter of deflected melt over a gap between both base materials. The variation of the interface between $R_{1}$ and $R_{4}$ leads to different area of $R_{1}$ and consequently different storage heat amount in $R_{1}$. The constant area of $R_{1}$ is, however, necessary during the joining stage. So, the reduced area of $R_{1}$ will be added on the top side where the heat source $q_{0}$ is applied. The increased heat conductions due to the enlarged surface of $R_{1}$ to $R_{2}$ and $R_{3}$ are considered as negligible. The temperature $T_{2}$ which is higher than the copper melting temperature is assigned to $R_{1}$ since this part demonstrates the deflected melt volume during the LIMBO process.

The parts $R_{2}$ and $R_{3}$ describe further molten parts of the interconnector due to the heat conduction within the interconnector which is not deflected towards the underlying substrate. Those parts are assumed as a liquid state due to the heat conduction from $R_{1}$ and therefore a temperature $T_{1}=$ $1100{ }^{\circ} \mathrm{C}$, which is just above the melting temperature of copper as for a boundary condition. The temperature of the remaining parts of the interconnector $R_{5}$ and $R_{6}$ is assumed with an ambient temperature $T_{0}=20{ }^{\circ} \mathrm{C}$ due to the high thermal conductivity of copper material.

The part $R_{4}$ demonstrates the initial melt on the copper layer surface which is expected to occur instantly when the deflected melt wets on the surface and the heat conduction starts. Hence, $R_{4}$ is assumed to have an area equal to the contact area between $R_{1}$ and $R_{4}$. An initial penetration depth of $2 \mu \mathrm{m}$ with a temperature $T_{1}$ is assumed for $R_{4}$ as well. The part $R_{7}$ has the ambient temperature $T_{0}$ at the beginning of the joining stage. The interface between $R_{7}$ and $R_{8}$ is set as a thermal insulation, since the thermal conductivity of the epoxy resin is negligible compared with the thermal conductivity of the copper material. The triangular mesh for the joining phase has a minimum element size of $2.5 \mu \mathrm{m}$ and a maximum element size of $10 \mu \mathrm{m}$ for the parts $R_{1}, R_{2}$, $R_{3}, R_{4}$, and $R_{7}$ and a physics-based triangular mesh for the parts $R_{5}$ and $R_{6}$ of the interconnector.

\subsubsection{Pre-heating stage of the overlap welding process}

For the pre-heating phase during the overlap welding process, the temperature distribution for a two-dimensional simulation is observed. As for the two-dimensional simulation, the static geometry is equal to the simulation for the joining stage of LIMBO process. However, the location of the heat source $q_{\mathrm{o}}$ and the outgoing temperature boundary is different. The position of the heat source is shifted by $200 \mu \mathrm{m}$ in $x$-direction to demonstrate the overlap welding process. To investigate the thermal load induced solely by the pre-heating stage during the overlap welding process, a sufficient cooling time is given before the overlap welding process. Therefore, the temperature of all parts is set to $20{ }^{\circ} \mathrm{C}$ at the beginning of the calculation. For the two-dimensional simulation, a triangular mesh is used. The element size is determined for all parts physically controlled. For the parts $R_{1}, R_{2}$, $R_{3}, R_{4}, R_{5}$, and $R_{6}$, the element size is set to extremely fine, for $R_{7}$ to finer, and for $R_{8}$ to normal.

\subsection{Further boundary conditions}

The heat convection is not considered within this model.

The two-dimensional simulation of the joining phase runs over a time of $2.5 \mathrm{~ms}$ in steps of $0.005 \mathrm{~ms}$ and the simulation of the pre-heating stages in two dimensions over a time of $80 \mathrm{~ms}$ in steps of $0.1 \mathrm{~ms}$. The MUMPS solver is used in both simulations.

The material properties of the interconnector and copper layer are assumed as a common copper material with an equal material properties. The temperature-dependent material properties such as thermal conductivity, density, and heat capacity of copper material are described in Appendix 1.

\section{Results}

\subsection{Destruction behavior of the weld joint due to the thermal load}

\subsubsection{Melt dynamics in the gap until the destruction}

The outgoing position for this investigation is when the preheating stage of LIMBO process is accomplished with a lenslike melt formation at the lower side of the upper base material (refer to Fig. 1). The laser beam is defocused with the mentioned z-shifter in sub-section 3.2 in a position $z=1.6 \mathrm{~mm}$ where the laser beam diameter is $220 \mu \mathrm{m}$ at the melt surface, respectively. As for the laser power, a target power with $P_{\text {target }}=500 \mathrm{~W}$ $\left(P_{\text {actual }}=483 \mathrm{~W}\right)$ is set and the duration of the pre-heating stage is set to $t=76 \mathrm{~ms}$. After the pre-heating stage, the focal lens of $\mathrm{z}$ shifter is adjusted to $z=1.1 \mathrm{~mm}$ with a velocity $v=100 \mathrm{~mm} / \mathrm{s}$ for the sudden vaporization of the melt surface. At the target position 
of the focal lens, the laser beam diameter is $163 \mu \mathrm{m}$, respectively. An additional laser beam irradiation after the deflection stage for $t=4 \mathrm{~ms}$ is given explicitly without moving the z-shifter to exceed the thermal threshold of the substrate.

Exceeding the tolerated thermal load during the joining stage, the melt between both base materials fails to maintain its form. Figure 4 shows the chronological shadow projection image sequence of the melt dynamics during the joining stage until the destruction.

The start of the joining stage is set to $t_{\mathrm{w}}=0 \mathrm{~ms}$ when the deflected melt wets on the copper layer. The heat conduction is initiated through the wetted melt on the underlying substrate. The further energy input leads to a symmetrical melt geometry formation after $t_{\mathrm{w}}=0.29 \mathrm{~ms}$ with $d=174 \mu \mathrm{m}$ in the gap (red box). Up to $t_{\mathrm{w}}=2.03 \mathrm{~ms}$, the melt volume remains stable and shows relative minor change in its shape. Only a minimal size increasement of the weld joint area is observed (yellow box). However, with an additional energy deposition, the connection suddenly becomes gaseous where the abrupt expansion of the connection is visible (blue box). This results in a rapid expulsion of the melt and a connection between two base materials is not given anymore (green box). The gray/white background of each image indicates a gap between both base materials.

\subsubsection{Weld joint development until the destruction}

The chronological sequence of the melt dynamic during the joining stage shows that the connection area between the deflected melt and the underlying base material increases with an additional energy input (refer to Fig. 5). Since the heat conduction is related with the connection area of the heat source, the temporal growth of the joint interface diameter is investigated dependent on the joining stage duration until the expulsion. The values in Fig. 5 are calculated within total five repetitions with an equal parameter set and the temporal variation of the interface diameter is considered in $\Delta t=100 \mu \mathrm{s}$ steps. The time of melt expulsion varies for every spot welding process even with the equally set process parameters. Therefore, the development of the joint interface diameter could only be considered until $t=1.8 \mathrm{~ms}$ with all five repetitions. In Appendix Table 1, the measured values are listed with the time of melt expulsion for every spot welding process. The mean value for the expulsion duration of five repetition is $t_{\text {expulsion }}=2.18 \pm 0.33 \mathrm{~ms}$, respectively.

The melt dynamic of the interface is constantly given during the whole joining stage. The joint interface diameter $d_{\mathrm{I}}$ from the initial melt wetting is in range of $50 \mu \mathrm{m}$. The interface diameter increases sharply until $t_{\mathrm{w}}=0.5 \mathrm{~ms}$ where the diameter reaches a value around $150 \mu \mathrm{m}$. After reaching the interface diameter of $150 \mu \mathrm{m}$, the temporal growth of the interface diameter is not clearly observed until the expulsion of the melt. In general, the range of standard deviation value of joint interface diameter is below $\sigma<20 \mu \mathrm{m}$. The region with the highest standard deviation value is from $t_{\mathrm{w}}=0.1 \mathrm{~ms}$ and $0.3 \mathrm{~ms}$ with the maximum deviation value with up to $\sigma_{\max }=42.5 \mu \mathrm{m}$ at $t=0.1 \mathrm{~ms}$. This value shows that the melt dynamic and heat supply to the underlying substrate are instable directly after the joining of both base materials.

\subsubsection{Investigation of the influence factor on the thermal load}

For the understanding of the experimental results regarding the destructive thermal damage to the substrate, the temperature at the interface between the copper layer and substrate below the beam center position is simulated (refer to Fig. 3 position $P_{1}$ ). One aim of the simulation is to determine whether the calculated temperature distributions align with experimentally observed thermal threshold of the substrate. Furthermore, the influence of different process parameters on the thermal stress is investigated. The time $t=0 \mathrm{~ms}$ for the simulation corresponds to the contacting moment of the melt and the copper layer. So, the heat conduction starts at $t_{\mathrm{w}}=0 \mathrm{~ms}$. The following conditions are considered for the simulation and the results are shown in Fig. 6: absorptivity A, initial temperatures of the melt in $R_{1}$, and the joint interface diameter $d$. The contact width is selected based on the mean value of the measured joint interface diameter from $d_{\mathrm{I}} 50 \mu \mathrm{m}$ and $150 \mu \mathrm{m}$.

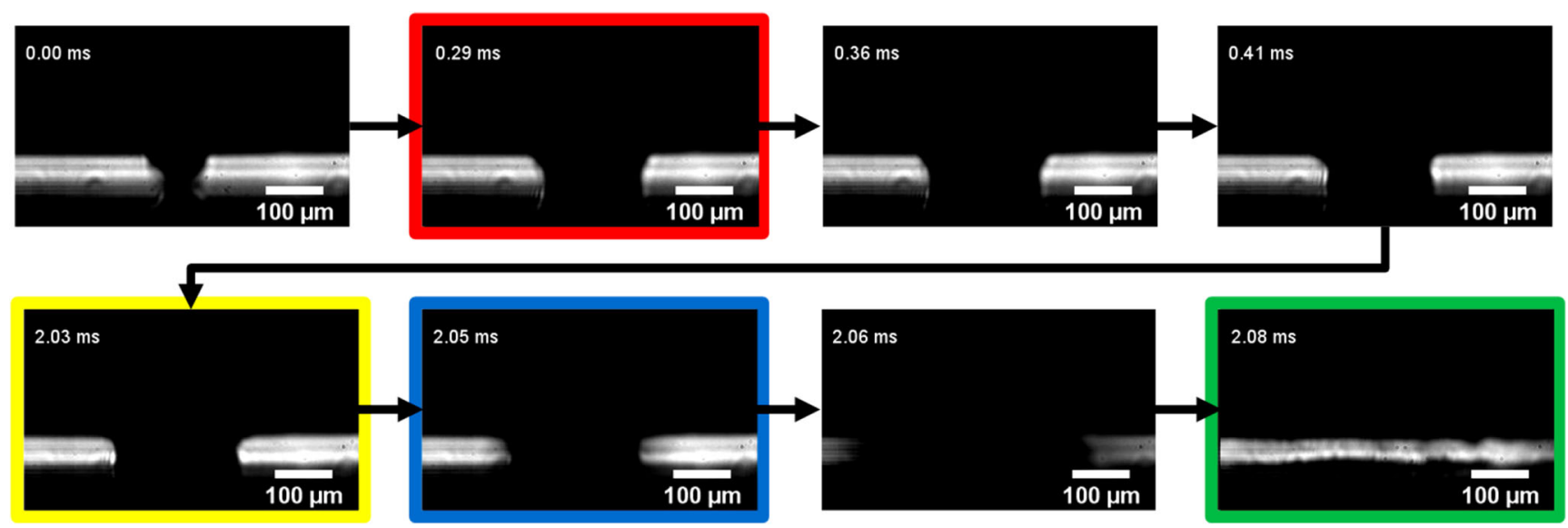

Fig. 4 Chronological shadow projection image of melt dynamics during the joining stage 


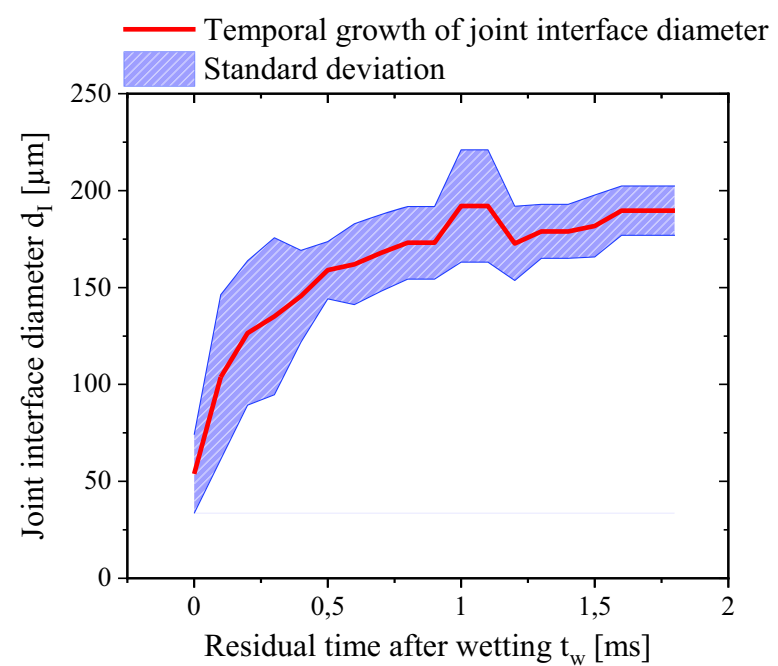

Fig. 5 Temporal growth of the joint interface diameter until $t_{\mathrm{w}}=1.8 \mathrm{~ms}$

For all considered influence factors, the temperature curve shows a comparable course. Within the range of $t<0.1 \mathrm{~ms}$, the temperature at the point $P_{1}$ rises sharply to a local maximum and drops until the local minimum is reached around between $t=[0.1-0.2] \mathrm{ms}$ depending on the applied value. When the local minimum is reached, the course rises once again, however with a lower gradient than the initial stage. The peak at the initial stage of heat conduction is caused by the heat transfer in $z$-direction and heat accumulation at $P_{1}$.

Influence of the absorptivity A fixed temperature $T_{2}=$ $1100{ }^{\circ} \mathrm{C}$ and the contact width $d=150 \mu \mathrm{m}$ are preliminary set for $R_{1}$. The absorptivity A is calculated in $5 \%$ steps from 15 to $35 \%$ and the resulting temperature curves for $P_{1}$ are shown in Fig. 6 left. The local maxima are achieved at a comparable time $t<0.1 \mathrm{~ms}$ and the temperature values at local maxima are between 550 and $580{ }^{\circ} \mathrm{C}$ for all calculations. The temperature curve recovers and exceeds the local maxima temperature value after reaching the local minima except for the absorptivity value $A=15 \%$ within the calculated time range. The temperature value differs at $t=2.5 \mathrm{~ms}$ between all considered absorptivity from 500 to $1050{ }^{\circ} \mathrm{C}$.

Influence of the initial temperature of $R_{1}$ A fixed absorptivity with $15 \%$ and a joint interface diameter with $150 \mu \mathrm{m}$ are considered for this calculation. The temperature $T_{2}$ in part $R_{1}$ is varied in $\Delta T=500{ }^{\circ} \mathrm{C}$ steps from 1100 to $2600{ }^{\circ} \mathrm{C}$ to demonstrate possible temperature range for the liquid copper (Fig. 6 middle). On the one hand, the local maxima are reached before $t<0.1 \mathrm{~ms}$ and the temperature of the initial peak rises from 550 to over $800{ }^{\circ} \mathrm{C}$ with the increasing temperature $T_{2}$. On the other hand, the slopes of the temperature course after the peak are approximately comparable for considered temperature range of $T_{2}$. The calculated temperature at $t=2.5 \mathrm{~ms}$ divers only for $T=62.3{ }^{\circ} \mathrm{C}$ even for high temperature difference between the initial temperature of $R_{1}$ with $\Delta T=1500{ }^{\circ} \mathrm{C}$.

Influence of the contact width of $R_{1}$ A fixed temperature of $T_{2}=1100{ }^{\circ} \mathrm{C}$ and the absorptivity of $A=15 \%$ are set to calculate the influence of the contact width of $R_{1}$. Three contact width values $50 \mu \mathrm{m}, 100 \mu \mathrm{m}$, and $150 \mu \mathrm{m}$ are calculated and the temperature development is shown in Fig. 6 right. The temperature courses are comparable with the Fig. 6 middle and the decreased temperature at $P_{1}$ is shown with reduced contact width. The differences between the temperature development for the contact width $100 \mu \mathrm{m}$ and $150 \mu \mathrm{m}$ are not distinguishable. By a given setting, the temperature of the local maxima range is only between 410 and $530{ }^{\circ} \mathrm{C}$ which shows the lowest range between the considered influence factors. The temperature difference at $t=2.5 \mathrm{~ms}$ is lower than $T=$ $10{ }^{\circ} \mathrm{C}$ and shows therefore the lowest range between three considered influence factors.
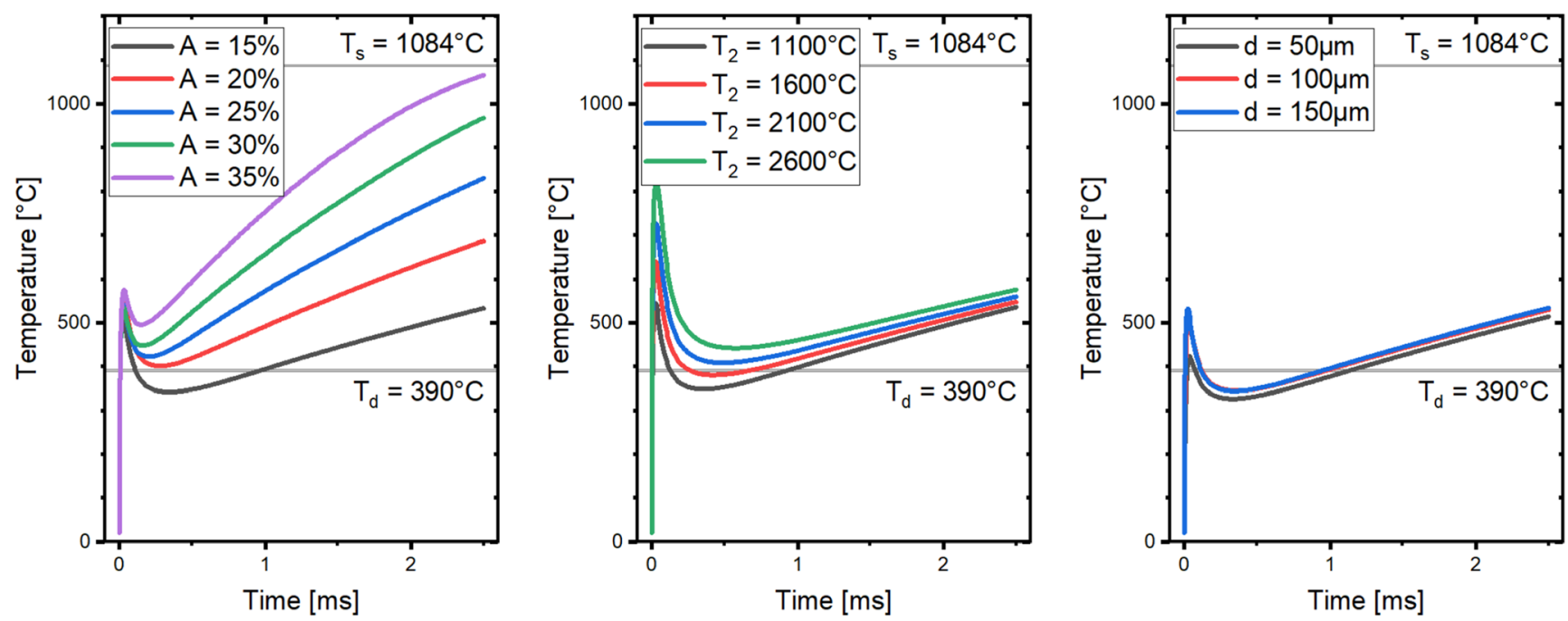

Fig. 6 Calculated temperature curve for different process conditions of the joining stage 


\subsection{Thermal load on the substrate during the overlap welding process}

\subsubsection{Investigation of the temperature development on the substrate during the pre-heating stage}

In this sub-section, the temperature development at point $P_{1}$ for the pre-heating stage of the overlap welding process is calculated (Fig. 7). The boundary conditions for the calculation are assumed with the absorptivity $A=15 \%$ and the joint interface diameter $d=150 \mu \mathrm{m}$. The assumed absorptivity is based on the absorptivity of liquid copper based on [10] and the joint interface diameter is based on the Fig. 4. Under the assumption that the pre-heating stage is initiated after sufficient cooling time as discussed in sub-section 4.2, the temperature in all parts is assigned with an ambient temperature.

As a result of a temperature development at the $P_{1}$, the temperature rises for the entire process time. The delamination temperature $T_{\mathrm{d}}$ is reached after $9.6 \mathrm{~ms}$ of the process duration. The evaporation of the epoxy resin is therefore expected to occur since the $T_{\mathrm{d}}$ is exceeded. As the heat conduction due to the heat supply continues, the $P_{1}$ reaches the copper melting temperature $1084^{\circ} \mathrm{C}$ at $t=65.4 \mathrm{~ms}$ and a the complete melting of the previous weld joint is expected. As a consequence, the epoxy resin at $P_{1}$ also reached the temperature above $1000{ }^{\circ} \mathrm{C}$ and the thermal destruction is unavoidable. The temperature gradient increases after the copper melting temperature due to the phase transition.

\subsubsection{Thermal destruction during the joining stage}

During the overlap welding process, the laser beam is irradiated $200 \mu \mathrm{m}$ distanced from the previous position of the LIMBO process. To investigate the thermal influence during the overlap welding process independent from the previous LIMBO welding process, a sufficient cooling time between each welding process is given for $t=1.5 \mathrm{~s}$ [6]. As for the applied process parameters, an

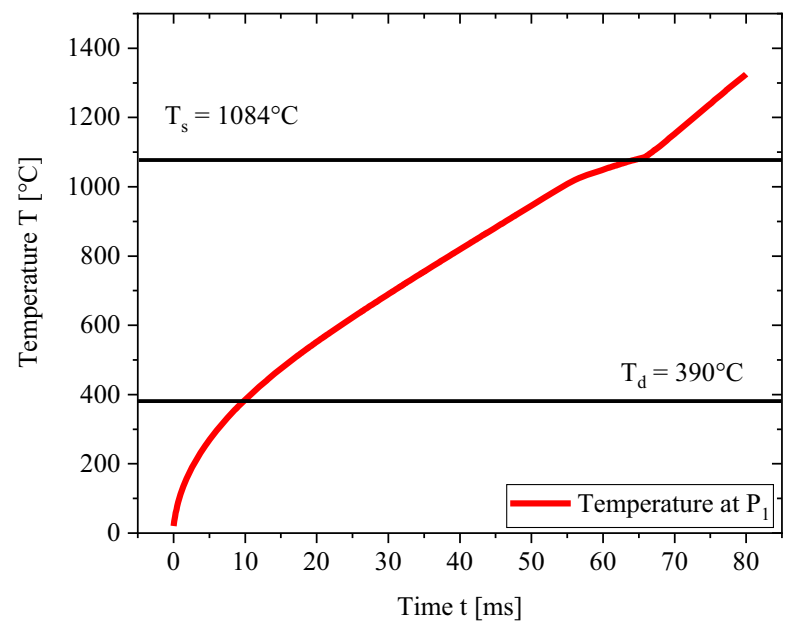

Fig. 7 Calculated temperature course of the pre-heating stage for the overlap welding process equal process set has been applied for the LIMBO process as mentioned in sub-section 5.1.1, except for the laser beam irradiation time during the joining stage with $t=0.5 \mathrm{~s}$, instead of $t=$ $4 \mathrm{~ms}$. By reducing the energy input after the deflection stage, a LIMBO weld joint is performed between two base materials without critical damage (refer to Fig. 8 red box). In Fig. 8, the outgoing position and the overlap welding process are shown in a chronological sequence with the shadow projection.

The course of weld joint formation in the gap during the overlap welding is comparable with the single LIMBO process. The weld joint expansion occurs on the left side of the previous weld joint. After the initial contact of the deflected melt on the underlying substrate (red box), the deflected melt and the previously conducted weld joint do not bond together yet. During the progress, the melt volume of deflected melt increases and the weld joint is expanded in a line weld joint form (yellow box). The melt pool in the gap expands volume and its form remains until the $t_{\mathrm{w}}=$ $2.23 \mathrm{~ms}$ from the initial contact (blue box). Exceeding the destruction thermal threshold after $t_{\mathrm{w}}=2.23 \mathrm{~ms}$, equal destruction behavior of the weld joint occurs. The remaining weld joint from the previous welding process is even observed after the destruction (green box). However, the weld joint area is decreased comparing before and after the overlap welding process. During the overlap welding process, the deflected melt adjoins the previous weld joint, and due to the heat conduction, a part of previous weld joint has reached its melting temperature. The molten part of the previous weld joint is splashed during the expulsion as well. The deviation of the previous weld joint diameter before and after the overlap welding process is $\Delta d=36 \mu \mathrm{m}$, respectively.

The overlap welding process is conducted in total with five repetitions with mentioned parameter setting. Even for the equally applied parameter set, a high deviation between each overlap welding process is observed. Within the five repetitions, the minimum duration for the destruction occurs at $t=1.3 \mathrm{~ms}$ and the maximum duration is at $t=3.6 \mathrm{~ms}$ where the measured time for the expulsion of the overlap welding process is $t_{\text {expulsion,overlap }}=$ $2.46 \pm 0.81 \mathrm{~ms}$, respectively. On the contrary, the joint interface diameter shows a stable value directly before the expulsion with $d_{\mathrm{I}}=273.31 \pm 10.8 \mu \mathrm{m}$, respectively.

\section{Discussion}

\subsection{Expulsion behavior of the weld joint}

After the deflected melt wets on the surface and melts the copper layer with storage heat and further energy deposition of the laser beam irradiation, the energy deposition should be terminated when a symmetrical weld joint is formed. However, if the laser beam irradiation continues, the substrate will be overheated due to the heat accumulation between the interface of the copper layer and the epoxy resin. The temperature threshold for epoxy resin is defined as the decomposition temperature $T_{\mathrm{d}}=390{ }^{\circ} \mathrm{C}$. 


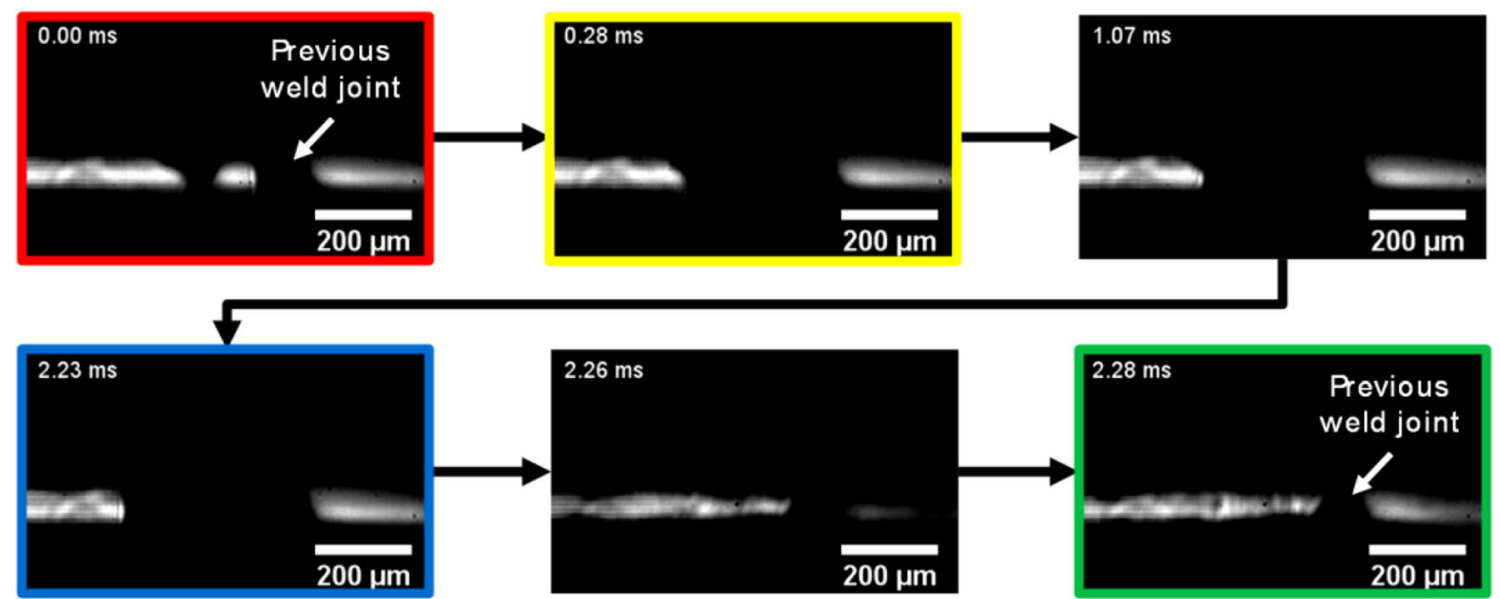

Fig. 8 Chronological shadow projection of melt dynamics during the overlap welding process

Consequently, the evaporation temperature of the epoxy resin will be reached and the epoxy resin decomposes into gaseous state. At the meantime, the melt penetration in the copper layer increases with further energy deposition over the entire thickness. As soon as the melt penetration has reached the interface between copper layer and epoxy resin, the formed gas in the substrate escapes through the melt. This results in a sudden expulsion of the melt. According to the Fig. 4, the tolerated heat conduction duration of LIMBO process given by setting is $t_{\mathrm{w}}=2.03 \mathrm{~ms}$ until the critical destruction of substrate occurs.

\subsection{Approximation of the welding condition during the joining stage}

Based on the experimentally gained destruction behavior of the weld joint, the welding condition during the joining stage is approximated with the simulated calculations in Fig. 6. Within about $0.1 \mathrm{~ms}$ after the first contact, the temperature at the interface to the substrate rises sharply, exceeding the delamination threshold $T_{\mathrm{d}}$ for each calculation. The local maximum temperature at the initial stage of joining is mostly influenced by the melt temperature $T_{2}$ at the contacting moment. The temperature $T_{2}$ demonstrates the amount of heat which is stored in the upper melt at the initial contacting moment. The main idea of the LIMBO process is to initiate the deflection stage as soon as the 'lens-like' melt is generated in order to minimize the process duration and consequently the 'lens-like' melt temperature. However, due to the low reproducibility of the laser beam welding process on a copper material, the moment of 'lens-like' melt fluctuates. Hence, the temperature $T_{2}$ is expected to be higher than the $1100{ }^{\circ} \mathrm{C}$. But, also $T_{2}=2600{ }^{\circ} \mathrm{C}$ is expected not to be realistic, since this value is just below the evaporation temperature of copper material. This would implement that the large melt pool volume has already evaporated when the joining stage begins. This contradicts the observation that the solidified weld joint area in the gap after the welding process is comparable with the interconnector area which is pressed due to the metal plume recoil pressure [6]. The temperatures of $T_{2}$ with $1600{ }^{\circ} \mathrm{C}$ and $2100{ }^{\circ} \mathrm{C}$ are therefore considered as possible approximation for the LIMBO process.

Considering the expulsion moment of the weld joint in Fig. 6 , the calculated value for all simulation in sub-section 5.1.3 does not exceed the melting temperature of copper at $t=2.08 \mathrm{~ms}$. However, the variation of the absorptivity A influences the temperature growth rate at $P_{1}$ highly after the initial contact of the melt (Fig. 7, left). Instead of $T_{2}$ with $1100{ }^{\circ} \mathrm{C}$, the temperature $2100{ }^{\circ} \mathrm{C}$ is applied for the calculation with the absorptivity $35 \%$; the calculated value of the temperature at $P_{1}$ after $t=2.08 \mathrm{~ms}$ can be expected. The approximated absorptivity during the joining stage aligns to the known absorptivity during the keyhole welding according to [11] with $32.2 \pm 8.3 \%$. Hence, the keyhole formation during the joining stage is also expected.

The contact width varies continuously until the expulsion as shown in the Fig. 5. However, the calculated value of the contact width from $50 \mu \mathrm{m}$ until $150 \mu \mathrm{m}$ results only minor change of the temperature at $P_{1}$. As the weld joint area increases, the heat conduction to the underlying substrate is influenced minimally. Hence, during the overlap welding process, more heat is expected to flow into the underlying substrate. However, the position of the heat supply moves as well and this results to another condition for the simulation. In total, the larger weld joint area during the joining stage of the overlap welding process is not expected to favor the thermal load due to the previous welding process.

\subsection{Exceeding the delamination temperature of the epoxy resin}

In Fig. 4, the symmetrical connection in the gap is given after $t_{\mathrm{w}}=0.29 \mathrm{~ms}$. The minimum residual time of the deflected melt $t_{\min }=0.29 \mathrm{~ms}$ on the underlying substrate is required to melt the copper layer surface and form a weld joint, respectively. The minimum residual time $t_{\mathrm{w}, \min }$ can be extended until the thermal destruction occurs due to the melt expulsion at $t=$ 
$2.08 \mathrm{~ms}$. However, when the heat supply continues after reaching the temperature threshold of epoxy resin through the heat conduction, a decomposition of epoxy resin is expected and the interface between copper layer and FR4 starts to delaminate. The delamination of the copper layer is considered as another thermal damage type which occurs before the expulsion. But, the start of the delamination due to thermal overload $t_{\text {delamination }}$ is only visible when the weld joint is metallographically examined (refer to Fig. 9 in Appendix). Hence, the delamination is expected to occur in time between $t=\left[0.29 \mathrm{~ms}<\mathrm{t}_{\text {delamination }}<2.03 \mathrm{~ms}\right]$, respectively.

The two-dimensional simulation results at point $P_{1}$ in Fig. 6 show for all calculated values a temperature over $T_{\mathrm{d}}$ even at the very beginning of the joining stage. Even the calculated simulation with the theoretically lowest energy input $\left(A=15 \%, T_{2}=1100{ }^{\circ} \mathrm{C}\right.$, and $\left.d=50 \mu \mathrm{m}\right)$ shows that the delamination temperature is exceeded with $T=533{ }^{\circ} \mathrm{C}$. After the temperature peak at the initial phase, the temperature at $P_{1}$ drops under the $T_{\mathrm{d}}$ for some calculated results until the process duration around $t=1 \mathrm{~ms}$. But, as the absorptivity A with $35 \%$ and initial melt temperature more than $1100{ }^{\circ} \mathrm{C}$ are discussed in previous sub-section, the exceeding of the delamination temperature for entire joining process seems to be given and the thermal damage of epoxy resin is not avoidable. However, the cross section of the previously investigated LIMBO welding results shows no delamination at the interface between the copper layer and epoxy resin (refer to Fig. 9 in Appendix) [6].

The heat conduction into the epoxy resin is neglected in this simulation model (refer to sub-section 3.3). The heat conduction therefore takes place only in the $x$-direction in the copper layer and accumulates at the interface between the copper layer and the epoxy resin. Even for the very low thermal conductivity value $k$ of epoxy resin with $0.3 \mathrm{~W} \mathrm{~m}^{-1} \mathrm{~K}^{-1}$, the heat at the interface will dissipate into the epoxy resin. Furthermore, the convection of the total system is also neglected, which dissipates the heat during the joining stage. In total, a lower temperature directly after the joining stage is expected on an experiment.

In addition, the validity of the known value for the delamination temperature of epoxy resin should be discussed for the LIMBO process. The testing condition for the decomposition temperature is determined by slowly heating up of the substrate at a rate of $10{ }^{\circ} \mathrm{C} / \mathrm{min}$ from ambient temperature to $550{ }^{\circ} \mathrm{C}$ and measures the mass reduction of epoxy resin due to the vaporization [12]. So, the delamination temperature is measured when the temperature of epoxy resin constantly increases in smaller step for a long term. But, since the calculated temperature fluctuates within $t=0.3 \mathrm{~ms}$ in the range of several hundred degrees Celsius, the known delamination temperature with the long-term investigation may not be applicable in this case.

\section{Conclusion and outlook}

\subsection{Conclusion}

In this paper, the LIMBO process is further investigated in terms of the thermal stress into the underlying sensitive substrate. The heat supply during the joining stage is continued until the critical destruction of the weld joint due to the thermal overload which is observed in the gap (refer to Fig. 4 green box). The weld destruction is expected when the decomposed epoxy resin evacuates through the melt which is measured at $t_{\text {expulsion }}=2.18 \pm$ $0.33 \mathrm{~ms}$. Consequently, the expulsion of the weld joint occurs and the substrate is damaged.

A simulative approach is carried out to determine the influence factor for the thermal load. The model is based on the geometrical value of the LIMBO weld joint through the experiments. The COMSOL Multiphysics® "Structural Mechanics Module" with "Heat Transfer in Solids" is used to calculate the two-dimensional temperature distributions based on the heat transfer equation. As for the influence factor for the thermal load, absorptivity A, initial melt temperature $T_{2}$, and joint interface diameter $d$ are considered. The variation of the absorptivity A gives the most influence to the thermal load where other factors are negligible.

Furthermore, the thermal load during the overlap welding process is also investigated. The equal model is used for the overlap welding process where only the position for the heat supply is moved $200 \mu \mathrm{m}$ in $x$-direction. Since both base materials are already connected, the heat conduction to the underlying substrate through the weld joint is regarded. The calculation leads to completely different result from the experiment that the temperature of the interface between the copper layer and epoxy resin exceeds the $1084{ }^{\circ} \mathrm{C}$ after $t=64.9 \mathrm{~ms}$. The joining stage of the overlap welding process is also experimentally investigated with an equal condition. Due to the heat conduction during the preheating stage, the copper layer is expected to be heated up. Therefore, it is expected to tolerate less thermal load during the joining stage. However, the expulsion occurs at $t_{\text {expulsion,overlap }}=$ $2.46 \pm 0.81 \mathrm{~ms}$ and this value is comparable with the joining stage of the single LIMBO process. Despite the high deviation value, the thermal load is not highly affected by the heat conduction through previously conducted weld.

\subsection{Outlook}

This paper applies a variety of approaches to understand the thermal stress during the LIMBO process. However, only limited understanding of the thermal stress into the underlying substrate is yet possible due to the simplified simulation model as well as the boundary conditions in section 3 and unclarified approximations mentioned in section 6 . As for the outlook, the simulation model should be firstly extended with heat convection and heat conductivity of epoxy resin. 
Furthermore, the demonstration of the varying weld joint geometry will give precise heat flux to the underlying substrate.

Also, the detailed description of the temperature-dependent heat conduction properties can calculate the heat flow more precisely. The introduction of the evaporation enthalpy can lead to an exact prediction of the required process time for the preheating phase with more precisely known parameters. Most importantly, the thermal threshold for the copper layer delamination in terms of extremely short-term thermal load should be defined. Once, the delamination temperature for extremely short-term thermal load is known, the maximum melt residual duration during the joining stage can be determined. The establishment of the minimum and maximum melt residual duration will be an indicator for the process stability.

Moreover, the heat supply position should be further adjusted during the joining stage since the keyhole welding is expected. The current simulation has a fixed heat supply position and this model does not demonstrate that the heat supply position varies as the keyhole penetrates the melt. As the keyhole depth increases, the distance between the heat supply and underlying substrate decreases, and therefore, higher heat flux is expected. In order to simulate the heat flux dependent to the keyhole penetration depth, the moment of keyhole formation as well as the keyhole development should be experimentally or simulative investigated. One possible approach for the keyhole measurement during the joining stage is by utilizing the interferometric principle.

As for the application of the LIMBO process, the welding process of various material combinations could be considered. The limited energy amount and precise control of the energy input to the base material may be applicable for conventionally challenging welding tasks such as copper and aluminum. The control of the energy input for the welding process could minimize the penetration depth and therefore suppress the intermetallic phase. Also, the welding process for the electronic devices could widen the material selection for the interconnector or metallic layer since the wettability of the solder is not required anymore.

Acknowledgements Open Access funding enabled and organized by Projekt DEAL.

Funding This work was supported by the Federal Ministry of Education and Research in the frame of the ThermoFreq project under the contract number $16 \mathrm{ES} 0701$.

\section{Appendix}

\section{Material properties for the simulation}

The material properties density $\rho$, thermal conductivity $k$, and heat capacity $c_{\mathrm{p}}$ are assigned a temperature dependence in three ranges. The first range extends from the ambient temperature $T_{0}$ to a temperature of $T_{\mathrm{s}}=1084{ }^{\circ} \mathrm{C}$ and describes the solid phase of copper. A second range from $T_{\mathrm{s}}$ to $T_{\mathrm{m}}=1089^{\circ} \mathrm{C}$ describes the transition from the solid to the liquid phase. The third range with a temperature greater than $T_{\mathrm{m}}$ describes the liquid phase. The values of the material properties are constant over the first range and the third range, respectively. For density and thermal conductivity over the second range, the different values for the solid and the liquid phase are connected by a linear equation. For the heat capacity over the second range, the specific enthalpy of fusion $h_{\text {fus }}$ of copper is divided by the difference of $T_{\mathrm{m}}$ and $T_{\mathrm{s}}$ to describe the energy need for the phase change from solid to liquid. The transition to the gas phase is neglected in this model.

For different types of copper, the density at room temperature is in the range of $880 \mathrm{~kg} \mathrm{~m}^{-3}[13,14]$ and is approximated to $880 \mathrm{~kg} \mathrm{~m}^{-3}$ for the solid phase. The density for the liquid phase is approximated with $750 \mathrm{~kg} \mathrm{~m}^{-3}$ according to [15]. The thermal conductivity for the solid phase is approximated in the range of $400 \mathrm{~W} \mathrm{~m}^{-1} \mathrm{~K}^{-1}$ for the room temperature of CuETP [13]. The thermal conductivity for the liquid phase is approximated according to [10] with $150 \mathrm{~W} \mathrm{~m}^{-1} \mathrm{~K}^{-1}$. The heat capacity for the solid phase is approximated with $386 \mathrm{~J} \mathrm{~kg}^{-1} \mathrm{~K}^{-1}$ for the room temperature of CuETP [13]. A molar enthalpy of fusion of $13 \mathrm{~kJ} \mathrm{~mol}^{-1}$ is used for the calculations. The heat capacity for the liquid phase is approximated to $636 \mathrm{~J} \mathrm{~kg}^{-1} \mathrm{~K}^{-1}$ according to [16].

Temperature-dependent density:

$\rho(T)= \begin{cases}880 \frac{\mathrm{kg}}{\mathrm{m}^{3}} & T<T_{\mathrm{s}} \\ 29065 \frac{\mathrm{kg}}{\mathrm{m}^{3}}-26 \frac{\mathrm{T}}{\mathrm{K}} \frac{\mathrm{kg}}{\mathrm{m}^{3}} & T_{\mathrm{s}}<T<T_{\mathrm{m}} \\ 750 \frac{\mathrm{kg}}{\mathrm{m}^{3}} & T_{\mathrm{m}}<T\end{cases}$

Temperature-dependent thermal conductivity:

$k(\mathrm{~T})= \begin{cases}400 \frac{W}{\mathrm{~m} / \mathrm{K}} & T<T_{\mathrm{s}} \\ 54600 \frac{W}{\mathrm{~m} / \mathrm{K}}-50 \frac{T}{K} \frac{W}{\mathrm{~m} / \mathrm{K}} & T_{\mathrm{s}}<T<T_{\mathrm{m}} \\ 150 \frac{W}{\mathrm{~m} / \mathrm{K}} & T_{\mathrm{m}}<T\end{cases}$

Temperature-dependent heat capacity:

$\mathrm{c}_{\mathrm{p}}(\mathrm{T})= \begin{cases}386 \frac{\mathrm{Jg} / \mathrm{K}}{\mathrm{kg}} & T<T_{\mathrm{s}} \\ h_{\text {fus }} /\left(T_{\mathrm{m}}-T_{\mathrm{s}}\right)=41 \times 10^{3} \frac{J}{\mathrm{~kg} / \mathrm{K}} & T_{\mathrm{s}}<T<T_{\mathrm{m}} \\ 636 \frac{\mathrm{Jg} / \mathrm{K}}{\mathrm{kg}} & T_{\mathrm{m}}<T\end{cases}$

\section{Cross section of the weld joint with the laser impulse metal bonding process with overlap pulsed welding}

An expanded weld joint diameter with comparable process parameter setting from [6] without any thermal destruction of the interface between the copper layer and epoxy resin. 
Fig. 9 Expanded weld joint within the total five LIMBO weld joints [6]

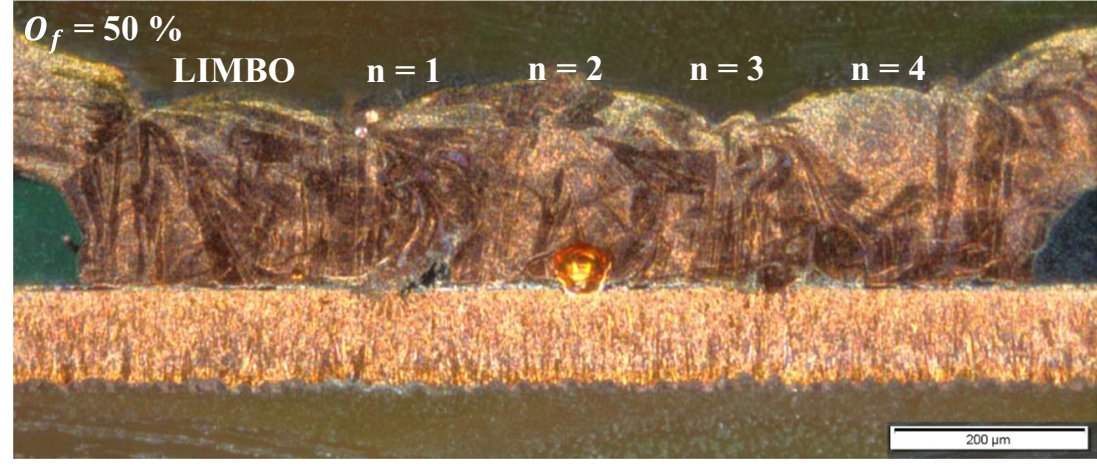

Table 1 Measured joint interface diameter for Fig. 5

\begin{tabular}{|c|c|c|c|c|c|c|c|}
\hline $\begin{array}{l}\text { Time } \\
{[\mathrm{ms}]}\end{array}$ & $\begin{array}{l}\text { Interface } \\
\quad \text { diameter } d_{1} \\
\quad[\mu \mathrm{m}]\end{array}$ & $\begin{array}{l}\text { Interface } \\
\quad \text { diameter } d_{2} \\
\quad[\mu \mathrm{m}]\end{array}$ & $\begin{array}{l}\text { Interface } \\
\quad \text { diameter } d_{3} \\
\quad[\mu \mathrm{m}]\end{array}$ & $\begin{array}{l}\text { Interface } \\
\quad \text { diameter } d_{4} \\
\quad[\mu \mathrm{m}]\end{array}$ & $\begin{array}{l}\text { Interface } \\
\quad \text { diameter } d_{5} \\
\quad[\mu \mathrm{m}]\end{array}$ & $\begin{array}{c}\text { Average value } \\
\quad d_{\mathrm{AVG}}[\mu \mathrm{m}]\end{array}$ & $\begin{array}{l}\text { Standard deviation } \\
\text { value } d_{\text {Stw. }}[\mu \mathrm{m}]\end{array}$ \\
\hline 0 & 53.45 & 56.90 & 31.03 & 37.93 & 89.66 & 53.79 & 20.32 \\
\hline 0.1 & 144.84 & 31.03 & 112.07 & 86.22 & 144.84 & 103.80 & 42.52 \\
\hline 0.2 & 170.69 & 62. .07 & 112.07 & 143.11 & 144.84 & 126.56 & 37.21 \\
\hline 0.3 & 184.48 & 62.07 & 131.03 & 153.46 & 144.84 & 135.18 & 40.55 \\
\hline 0.4 & 184.48 & 113.79 & 131.03 & 153.46 & 144.84 & 145.52 & 23.66 \\
\hline 0.5 & 184.48 & 162.08 & 139.67 & 153.46 & 155.18 & 158.97 & 14.68 \\
\hline 0.6 & 184.48 & 187.94 & 148.28 & 134.49 & 155.18 & 162.07 & 20.83 \\
\hline 0.7 & 184.48 & 198.28 & 148.28 & 153.46 & 155.18 & 167.94 & 19.77 \\
\hline 0.8 & 184.48 & 198.28 & 148.28 & 179.31 & 155.18 & 173.11 & 18.65 \\
\hline 0.9 & 184.48 & 198.28 & 148.28 & 179.31 & 155.18 & 173.11 & 18.65 \\
\hline 1 & 184.48 & 198.28 & 243.11 & 179.31 & 155.18 & 192.07 & 29.07 \\
\hline 1.1 & 184.48 & 198.28 & 243.11 & 179.31 & 155.18 & 192.07 & 29.07 \\
\hline 1.2 & 184.48 & 198.28 & 146.56 & 179.31 & 155.18 & 172.76 & 19.12 \\
\hline 1.3 & 184.48 & 198.28 & 177.59 & 179.31 & 155.18 & 178.97 & 13.94 \\
\hline 1.4 & 184.48 & 198.28 & 177.59 & 179.31 & 155.18 & 178.97 & 13.94 \\
\hline 1.5 & 198.28 & 198.28 & 177.59 & 179.31 & 155.18 & 181.73 & 15.97 \\
\hline 1.6 & 210.35 & 198.28 & 177.59 & 179.31 & 182.76 & 189.66 & 12.67 \\
\hline 1.7 & 210.35 & 198.28 & 177.59 & 179.31 & 182.76 & 189.66 & 12.67 \\
\hline 1.8 & 210.35 & 198.28 & 177.59 & 179.31 & 182.76 & 189.66 & 12.67 \\
\hline 1.9 & 210.35 & 198.28 & 177.59 & 179.31 & Expulsion & & \\
\hline 2 & Expulsion & 198.28 & 177.59 & 179.31 & & & \\
\hline 2.1 & & 222.42 & 177.59 & 189.66 & & & \\
\hline 2.2 & & Expulsion & 177.59 & 189.66 & & & \\
\hline 2.3 & & & 177.59 & 200.01 & & & \\
\hline 2.4 & & & 177.59 & 224.14 & & & \\
\hline 2.5 & & & 177.59 & Expulsion & & & \\
\hline 2.6 & & & 177.59 & & & & \\
\hline 2.7 & & & 177.59 & & & & \\
\hline 2.8 & & & Expulsion & & & & \\
\hline \multicolumn{8}{|l|}{2.9} \\
\hline 3 & & & & & & & \\
\hline
\end{tabular}


Open Access This article is licensed under a Creative Commons Attribution 4.0 International License, which permits use, sharing, adaptation, distribution and reproduction in any medium or format, as long as you give appropriate credit to the original author(s) and the source, provide a link to the Creative Commons licence, and indicate if changes were made. The images or other third party material in this article are included in the article's Creative Commons licence, unless indicated otherwise in a credit line to the material. If material is not included in the article's Creative Commons licence and your intended use is not permitted by statutory regulation or exceeds the permitted use, you will need to obtain permission directly from the copyright holder. To view a copy of this licence, visit http://creativecommons.org/licenses/by/4.0/.

\section{References}

1. J. Helm, A. Schulz, A. Olowinsky, A. Dohrn, R. Poprawe: Welding in the world, 64, (2020)

2. Z. Wang, J.P. Oliveira, Z. Zeng, X. Bu, B. Peng, X. Shao: Optics and laser technology, 111, (2019)

3. J.P. Oliveria, Z. Zeng, S. Berveiller, D. Bouscaud, F.M. Braz Fernandes, R.M. Miranda, N. Zhou: Materials and design, 148, (2018)

4. X. Tang, S. Deng, F. Lu, H. Cui, Y. Luo: Welding in the world, 63, (2019)

5. J.P. Oliveria, N. Schell, N. Zhou, L. Wood, O. Benafan: Materials and design, 162, (2019)

6. Chung W, Haeusler A, Olowinsky A, Gillner A, Poprawe R (2018) JLMN 13:2

7. W.-S. Chung, J. Reska, A. Olowinsky, A. Gillner (2020) Investigation of the melt dynamics during the laser impulse metal bonding process with keyhole measurement. Procedia CIPR( 94): 753-757
8. Britten SW (2016) Laser Tech J 2:53

9. Poprawe R (2005) Lasertechnik für die Fertigung: Grundlagen, Perspektiven und Beispiele für den innovativen Ingenieur ; mit 26 Tabellen. VDI-Buch. Springer, Berlin

10. Blom A, Dunias P, van Engen P et al. (2003) Process spread reduction of laser microspot welding of thin copper parts using real-time control. In: Pique A, Sugioka K, Herman PR et al. (eds) Photon Processing in Microelectronics and Photonics II. SPIE, p 493

11. Okamoto Y, Nishi N, Nakashiba S et al. Smart laser micro-welding of difficult-to-weld materials for electronic industry: 935102. https://doi.org/10.1117/12.2076232

12. IPC - Association Connecting Electronics Industries (4/06) IPCTM-650 Test Methods Manual - TM 2.4.24.6 Decomposition Temperature (Td) of Laminate Material Using TGA 4/06. https:// www.ipc.org/TM/2-4_2-4-24-6.pdf. Accessed 08 Oct 2019

13. DKI Werkstoff-Datenblätter, Cu-ETP. https://www.kupferinstitut. de/fileadmin/user_upload/kupferinstitut.de/de/Documents/Shop/ Verlag/Downloads/Werkstoffe/Datenblaetter/Kupfer/Cu-ETP.pdf.

14. DKI Werkstoff-Datenblätter, CuFe2P. https://www.kupferinstitut. de/fileadmin/user_upload/kupferinstitut.de/de/Documents/Shop/ Verlag/Downloads/Werkstoffe/Datenblaetter/Niedriglegierte/ CuFe2P.pdf.

15. Brillo J, Egry I (2003) Density determination of liquid copper, nickel, and their alloys. Int J Thermophys 24(4):1155-1170. https://doi.org/10.1023/A:1025021521945

16. Hüpf T, Cagran C, Kaschnitz E, Pottlacher G (2010) Thermophysical properties of five binary copper-nickel alloys. Int J Thermophys 31(4-5):966-974. https://doi.org/10.1007/ s10765-010-0732-x

Publisher's note Springer Nature remains neutral with regard to jurisdictional claims in published maps and institutional affiliations. 